\begin{abstract}
Correspondence
Elvira Garza-González

elvira_garza_gzz@yahoo.com
\end{abstract}

Received 5 September 2009

Accepted 9 December 2009

\section{Diversity of staphylococcal cassette chromosome mec structures in coagulase-negative staphylococci and relationship to drug resistance}

\author{
Elvira Garza-González, ${ }^{1}$ Daniel López, ${ }^{1}$ Cesar Pezina, ${ }^{1}$ Walter Muruet, ${ }^{1}$ \\ Virgilio Bocanegra-García, ${ }^{2}$ Ivan Muñoz, ${ }^{1}$ Camilo Ramírez ${ }^{1}$ \\ and Jorge M. LLaca-Díaz ${ }^{3}$
}
${ }^{1}$ Departamento de Microbiología, Facultad de Medicina, Universidad Autónoma de Nuevo León, Monterrey Nuevo Leon 64460, Mexico
${ }^{2}$ Departamento de Biología Molecular y Bioingeniería, UAM Reynosa Aztlán, Universidad Autónoma de Tamaulipas, Tamaulipas, Mexico
${ }^{3}$ Hospital Universitario Dr José Eleuterio González, Universidad Autónoma de Nuevo León, Monterrey Nuevo Leon 64460, Mexico

\begin{abstract}
The objective of this study was to determine the distribution of staphylococcal cassette chromosome mec (SCCmec) elements in meticillin-resistant coagulase-negative staphylococci (MR-CoNS) isolated from a tertiary-care hospital in Mexico and to examine the relationship to drug resistance. Fifty selected MR-CoNS isolates collected from catheters $(n=15)$, blood $(n=15)$, bone $(n=9)$, bronchial lavage $(n=2)$ and urine $(n=2)$ and one isolate each from an abscess, cerebrospinal fluid, eye, pleural effusion, synovial fluid, tracheal aspirate and wound secretion were examined. Susceptibility testing was performed by the broth microdilution method. SCCmec types were determined by multiplex PCR and PFGE was carried out as described previously for Staphylococcus aureus. Among the MR-CoNS strains studied, the most frequently isolated species were Staphylococcus epidermidis $(n=26)$ and Staphylococcus haemolyticus ( $n=13)$. Staphylococcus cohnii $(n=5)$, Staphylococcus hominis $(n=3)$, Staphylococcus sciuri $(n=1)$, Staphylococcus pasteuri $(n=1)$ and the recently described species Staphylococcus pettenkoferi $(n=1)$ were also identified. The most frequent MR-CoNS genotype identified was $\mathrm{SCC} m e c$ type IVa in S. epidermidis isolates, which also showed a high diversity in their PFGE patterns. A clone was found that amplified both SCCmec III and V elements in five isolates examined. The single MR S. pettenkoferi isolate harboured SCCmec type IVd and the single MR $S$. pasteuri isolate harboured SCCmec type I. The carriage of SCCmec type III was associated with resistance or intermediate resistance to meropenem $(P<0.05)$. These results confirm the high prevalence of $S$. epidermidis SCCmec IVa and the high genetic diversity among MR-CoNS strains. As far as is known, this is the first report describing the newly identified $S$. pettenkoferi possessing SCCmec IVd and S. pasteuri harbouring SCCmec type I. MR-CoNS harbouring $\mathrm{SCC} m e c$ type III were found to be more resistant to meropenem.
\end{abstract}

\section{INTRODUCTION}

In recent years, coagulase-negative staphylococci (CoNS) have emerged as important causative agents of illness,

Abbreviations: CoNS, coagulase-negative staphylococci; MR, meticillinresistant; MRSA, meticillin-resistant Staphylococcus aureus; MRSE, meticillin-resistant Staphylococcus epidermidis; SCCmec, staphylococcal cassette chromosome mec.

The GenBank/EMBL/DDBJ accession numbers for the partial DNA sequences of the $16 \mathrm{~S}$ rRNA gene and SCCmec type $\mathrm{IVd}$ of Staphylococcus pettenkoferi are GQ145596 and GQ145595, respectively. frequently involved in nosocomial infections related to medical devices and prostheses in immunocompromised patients (Curtis \& Shetty, 2008; Falcone et al., 2007; Viale \& Stefani, 2006). This scenario has worsened because of drug-resistant CoNS, such as meticillin-resistant (MR)CoNS (Lyytikäinen et al., 2002).

Meticillin resistance in staphylococci is conferred by the penicillin-binding protein PBP2a ( $\mathrm{PBP} 2^{\prime}$ ) encoded by the mecA gene and located on the staphylococcal cassette chromosome mec (SCCmec) (Katayama et al., 2000). Eight different SCCmec types (I-VIII) have been identified and 
Table 1. Distribution of SCCmec cassettes among MR staphylococcal isolates

\begin{tabular}{|c|c|c|c|c|c|c|c|c|c|c|c|c|c|c|c|}
\hline \multirow[t]{2}{*}{ Isolate } & \multirow[t]{2}{*}{ Species } & \multirow{2}{*}{$\begin{array}{c}\text { Patient } \\
\text { age } \\
\text { (years) }\end{array}$} & \multirow{2}{*}{$\begin{array}{c}\text { Patient } \\
\text { gender } \\
\text { (male/female) }\end{array}$} & \multirow{2}{*}{$\begin{array}{l}\text { Specimen } \\
\text { source }\end{array}$} & \multirow[t]{2}{*}{$c c r$} & \multirow[t]{2}{*}{ mec complex } & \multirow{2}{*}{$\begin{array}{c}\text { SCCmec } \\
\text { type }\end{array}$} & \multicolumn{8}{|c|}{$\operatorname{MIC}\left(\mu \mathrm{g} \mathrm{ml}^{-1}\right)^{\star}$} \\
\hline & & & & & & & & AMX & TZP & LVX & CRO & AMP & MIN & TIG & MEM \\
\hline 1492 & S. epidermidis & 17 & M & Catheter & NT & A & III & $>8 / 4$ & $>16 / 4$ & 32 & 64 & $>16$ & 4 & 2 & $>16$ \\
\hline 395 & S. epidermidis & 1 & M & Catheter & NT & $\mathrm{A}$ & III & $2 / 1$ & $2 / 4$ & 8 & 32 & $>16$ & $<0.25$ & 0.06 & 4 \\
\hline 4982 & S. epidermidis & 77 & M & Catheter & NT & $\mathrm{A}$ & III & $4 / 2$ & $2 / 4$ & $>32$ & 32 & 8 & 8 & 2 & 8 \\
\hline 1237 & S. epidermidis & 78 & M & Bone & NT & NT & III and IVa & $4 / 2$ & $8 / 4$ & $>32$ & $>64$ & $>16$ & 0.5 & 0.25 & $>16$ \\
\hline 2390 & S. epidermidis & 0 & $\mathrm{~F}$ & Catheter & NT & $A+B$ & III and IVa & $8 / 4$ & $>16 / 4$ & 4 & $>64$ & $>16$ & $<0.25$ & 0.125 & $>16$ \\
\hline 1085 & S. epidermidis & 35 & M & Blood & NT & B & III and IVa & $>8 / 4$ & $>16 / 4$ & $>32$ & $>64$ & $>16$ & 0.25 & 0.125 & $>16$ \\
\hline 118 & S. epidermidis & 89 & $\mathrm{~F}$ & Tracheal aspirate & 2 & $\mathrm{~B}$ & III and IVa & $8 / 4$ & $16 / 4$ & $>32$ & $>64$ & $>16$ & $<0.25$ & 0.06 & $>16$ \\
\hline 488 & S. epidermidis & 50 & M & Urine & 2 & $\mathrm{~B}$ & III and IVa & $8 / 4$ & $8 / 4$ & $>32$ & 32 & $>16$ & $<0.25$ & 0.06 & $>16$ \\
\hline 965 & S. epidermidis & 0 & $\mathrm{~F}$ & Blood & 3 & $\mathrm{~A}$ & III and V & $>8 / 4$ & $16 / 4$ & 8 & $>64$ & 16 & 0.5 & 0.25 & 16 \\
\hline 1439 & S. epidermidis & 1 & $\mathrm{M}$ & Catheter & 3 & $\mathrm{~A}$ & III and V & $>8 / 4$ & $16 / 4$ & 8 & $>64$ & 16 & 0.5 & 0.5 & 16 \\
\hline 1543 & S. epidermidis & 0 & M & Catheter & 3 & $\mathrm{~A}$ & III and V & $8 / 4$ & $8 / 4$ & 4 & $>64$ & 8 & $<0.25$ & 0.125 & 8 \\
\hline 1955 & S. epidermidis & 2 & $\mathrm{~F}$ & Catheter & 3 & $\mathrm{~A}$ & III and V & $8 / 4$ & $8 / 4$ & 4 & $>64$ & 8 & 0.5 & 0.125 & 8 \\
\hline 1981 & S. epidermidis & 17 & M & Catheter & 3 & A & III and V & $8 / 4$ & $8 / 4$ & 4 & $>64$ & 8 & 0.5 & 0.5 & 8 \\
\hline 1086 & S. epidermidis & 35 & M & Bone & 2 & NT & IVa & $1 / 0.5$ & $1 / 4$ & $>32$ & 16 & $>16$ & $<0.25$ & 0.125 & 2 \\
\hline 1458 & S. epidermidis & 0 & $\mathrm{~F}$ & $\mathrm{CSF}$ & 2 & NT & IVa & $1 / 0.5$ & $2 / 4$ & 0.12 & 16 & $>16$ & $>8$ & 0.25 & 4 \\
\hline 1102 & S. epidermidis & 60 & M & Blood & 2 & $\mathrm{~B}$ & IVa & $1 / 0.5$ & $8 / 4$ & 0.12 & 32 & 8 & 0.5 & 0.25 & 2 \\
\hline 778 & S. epidermidis & 35 & $\mathrm{M}$ & Catheter & 2 & B & IVa & $2 / 1$ & $2 / 4$ & 0.12 & 16 & $>16$ & 1 & 0.5 & 2 \\
\hline 960 & S. epidermidis & 72 & $\mathrm{~F}$ & Blood & 2 & NT & IVa & $2 / 1$ & $2 / 4$ & 4 & 16 & $>16$ & 0.5 & 0.25 & 4 \\
\hline 1006 & S. epidermidis & 23 & M & Bone & 2 & NT & IVa & $2 / 1$ & $4 / 4$ & 0.12 & 16 & $>16$ & 0.5 & 0.125 & 2 \\
\hline 4981 & S. epidermidis & 70 & $\mathrm{~F}$ & Catheter & 2 & NT & IVa & $2 / 1$ & $4 / 4$ & 4 & 32 & 8 & $<0.25$ & 0.06 & 4 \\
\hline 2078 & S. epidermidis & 80 & M & Synovial & 2 & B & IVa & $1 / 0.5$ & $>16 / 4$ & 4 & 16 & $>16$ & 8 & 2 & 2 \\
\hline 1083 & S. epidermidis & 32 & M & Bone & NT & $\mathrm{A}$ & $\mathrm{V}$ & $1 / 0.5$ & $4 / 4$ & 0.12 & 8 & 8 & 0.5 & 0.25 & 2 \\
\hline 848 & S. epidermidis & 54 & $\mathrm{~F}$ & Blood & NT & $\mathrm{A}$ & NT & $>8 / 4$ & $>16 / 4$ & 2 & $>64$ & $>16$ & 0.5 & 0.25 & $>16$ \\
\hline 1739 & S. epidermidis & 50 & M & Pleural effusion & 2 & $\mathrm{~B}$ & NT & $0.5 / 0.25$ & $>16 / 4$ & $>32$ & 16 & 16 & 0.5 & 0.25 & 1 \\
\hline 353 & S. epidermidis & 0 & $\mathrm{~F}$ & Blood & 2 and 5 & A & NT & $1 / 0.5$ & $>16 / 4$ & $>32$ & 8 & $>16$ & $>8$ & 0.25 & 2 \\
\hline 1089 & S. epidermidis & 0 & $\mathrm{~F}$ & Bone & NT & $\mathrm{B}$ & NT & $1 / 0.5$ & $2 / 4$ & 0.06 & 16 & $>16$ & 0.5 & 0.25 & 2 \\
\hline 1460 & S. haemolyticus & 54 & $\mathrm{~F}$ & Blood & NT & NT & II & $>8 / 4$ & $>16 / 4$ & $>32$ & $>64$ & 16 & $>8$ & $>16$ & $>16$ \\
\hline 2165 & S. haemolyticus & 80 & M & Catheter & 1 & NT & II & $>8 / 4$ & $>16 / 4$ & $>32$ & $>64$ & $>16$ & 0.5 & 0.25 & $>16$ \\
\hline 1628 & S. haemolyticus & 66 & $\mathrm{~F}$ & Blood & 5 & NT & II and V & $0.5 / 0.25$ & $2 / 4$ & 4 & 16 & 4 & $<0.25$ & 0.125 & 0.5 \\
\hline 6196 & S. haemolyticus & 27 & M & Bronchial lavage & 5 & NT & II and V & $2 / 1$ & $4 / 4$ & 4 & 32 & 4 & 1 & 0.06 & 1 \\
\hline 12 & S. haemolyticus & 88 & M & Abscess & 5 & NT & II and V & $4 / 2$ & $16 / 4$ & 4 & 32 & 16 & $<0.25$ & 0.125 & 2 \\
\hline 28 & S. haemolyticus & 66 & $\mathrm{M}$ & Blood & NT & NT & II and V & $4 / 2$ & $8 / 4$ & $>32$ & 32 & $>16$ & $<0.25$ & 0.06 & 2 \\
\hline 2215 & S. haemolyticus & 1 & $\mathrm{M}$ & Catheter & 3 & NT & III and V & $0.12 / 0.06$ & $>16 / 4$ & 4 & 8 & 2 & $<0.25$ & 0.5 & $<0.12$ \\
\hline 1879 & S. haemolyticus & 37 & $\mathrm{~F}$ & Wound & NT & NT & $\mathrm{V}$ & $8 / 4$ & $>16 / 4$ & 2 & $>64$ & $>16$ & $<0.25$ & 0.25 & 8 \\
\hline 1069 & S. haemolyticus & 62 & $\mathrm{~F}$ & Urine & NT & NT & $\mathrm{V}$ & $>8 / 4$ & $>16 / 4$ & $>32$ & $>64$ & $>16$ & $<0.25$ & 0.25 & $>16$ \\
\hline 286 & S. haemolyticus & 47 & M & Bronchial lavage & NT & NT & NT & $>8 / 4$ & $>16 / 4$ & $>32$ & $>64$ & $>16$ & $<0.25$ & 0.125 & $>16$ \\
\hline 1222 & S. haemolyticus & 2 & M & Blood & NT & NT & NT & $>8 / 4$ & $>16 / 4$ & $>32$ & $>64$ & $>16$ & 0.5 & 0.5 & $>16$ \\
\hline 988 & S. haemolyticus & 0 & $\mathrm{~F}$ & Eye & NT & NT & NT & $>8 / 4$ & $>16 / 4$ & 4 & $>64$ & $>16$ & 0.5 & 0.25 & $>16$ \\
\hline
\end{tabular}


Table 1. cont.

\begin{tabular}{|c|c|c|c|c|c|c|c|c|c|c|c|c|c|c|c|}
\hline \multirow[t]{2}{*}{ Isolate } & \multirow[t]{2}{*}{ Species } & \multirow{2}{*}{$\begin{array}{l}\text { Patient } \\
\text { age } \\
\text { (years) }\end{array}$} & \multirow{2}{*}{$\begin{array}{c}\text { Patient } \\
\text { gender } \\
\text { (male/female) }\end{array}$} & \multirow{2}{*}{$\begin{array}{l}\text { Specimen } \\
\text { source }\end{array}$} & \multirow[t]{2}{*}{$c c r$} & \multirow[t]{2}{*}{ mec complex } & \multirow{2}{*}{$\begin{array}{c}\text { SCCmec } \\
\text { type }\end{array}$} & \multicolumn{8}{|c|}{$\operatorname{MIC}\left(\mu \mathrm{g} \mathrm{ml}^{-1}\right)^{\star}$} \\
\hline & & & & & & & & AMX & TZP & LVX & CRO & AMP & MIN & TIG & MEM \\
\hline 2452 & S. haemolyticus & 7 & M & Blood & 1 & NT & NT & $>8 / 4$ & $>16 / 4$ & $>32$ & $>64$ & $>16$ & 0.5 & 0.25 & $>16$ \\
\hline 663 & S. hominis & 27 & M & Bone & NT & NT & NT & $0.25 / 0.12$ & $>16 / 4$ & 2 & 2 & 4 & 0.5 & 0.125 & 0.12 \\
\hline 1494 & S. hominis & 36 & M & Bone & NT & NT & NT & $0.25 / 0.12$ & $1 / 4$ & 8 & 4 & $>16$ & $>8$ & 2 & 1 \\
\hline 397 & S. hominis & 0 & $\mathrm{~F}$ & Blood & 1 and 5 & A & III & $>8 / 4$ & $>16 / 4$ & $>32$ & 32 & 16 & $>8$ & 2 & $>16$ \\
\hline 57 & S. cohnii & NA & M & Blood & NT & NT & NT & $>8 / 4$ & $>16 / 4$ & $>32$ & $>64$ & $>16$ & $>8$ & $>16$ & $>16$ \\
\hline 2074 & S. cohnii & 52 & $\mathrm{~F}$ & Catheter & NT & NT & NT & $>8 / 4$ & $8 / 4$ & $>32$ & $>64$ & 8 & $<0.25$ & 0.5 & 2 \\
\hline 349 & S. cohnii & 53 & M & Catheter & NT & NT & NT & $8 / 4$ & $>16 / 4$ & $>32$ & $>64$ & 4 & $>8$ & 2 & 2 \\
\hline 3281 & S. cohnii & 0 & $\mathrm{~F}$ & Blood & NT & NT & NT & $2 / 1$ & $8 / 4$ & 0.25 & $>64$ & 1 & $>8$ & 0.125 & 0.25 \\
\hline 849 & S. cohnii & 20 & $\mathrm{~F}$ & Catheter & NT & NT & NT & $4 / 2$ & $8 / 4$ & $>32$ & 32 & 1 & 1 & 0.25 & 0.5 \\
\hline 2658 & S. pettenkoferi & 0 & M & Blood & NT & NT & IVd & $>8 / 4$ & $>16 / 4$ & $>32$ & $>64$ & 16 & $<0.25$ & 0.25 & $>16$ \\
\hline 2247 & S. sciuri & 26 & M & Bone & NT & NT & NT & $4 / 2$ & $16 / 4$ & 0.5 & 32 & 2 & $<0.25$ & 0.25 & 1 \\
\hline 3223 & S. pasteuri & 0 & $\mathrm{~F}$ & Bone & NT & NT & I & $\leqslant 2$ & $8 / 4$ & 4 & 4 & $>8$ & $<0.25$ & 0.25 & 1 \\
\hline
\end{tabular}

NA, Data not available; NT, non-typable.

${ }^{*}$ AMX, amoxicillin/clavulanic acid; TZP, piperacillin/tazobactam; LVX, levofloxacin; CRO, ceftriaxone; AMP, ampicillin; MIN, minocycline; TIG, tigecycline; MEM, meropenem. 
are categorized by different sets of chromosome cassette recombinase $(\mathrm{ccr})$ genes and differences in the mec gene complex (Chongtrakool et al., 2006; Ito et al., 2001; Ma et al., 2002; Zhang et al., 2009). Although the mec origin remains unknown, it has been suggested that SCCmec can be transferred between staphylococci and that mecApositive CoNS may act as potential SCCmec donors, accounting for the rise in new MR Staphylococcus aureus (MRSA) clones (Hanssen \& Ericson Sollid, 2006; Musser \& Kapur, 1992). In relation to the origin of the SCCmec complex, it has been suggested that Macrococcus caseolyticus may be closely associated with the origin of the meticillin resistance gene complex in S. aureus (Baba et al., 2009).

The objective of this study was to determine the distribution of SCCmec elements in MR-CoNS isolated from a tertiary-care hospital in Mexico and to examine its relationship to drug resistance.

\section{METHODS}

Bacterial cultures. A total of 215 CoNS isolates collected between 15 May 2006 and 15 November 2006 were included in this study, and all collection and study protocols were approved by the Ethics Committee of the Universidad Autónoma de Nuevo León, Mexico. Isolates were identified by conventional biochemical tests (Bannerman \& Peacock, 2007) and via the use of API galleries (bioMérieux). All strains met the laboratory criteria for a significant pathogen, and were considered probable causative agents of a hospital-acquired infection. For all isolates, resistance to meticillin was determined by a cefoxitin disc test with the interpretative criteria $\leqslant 24$ (resistant) and $\geqslant 25$ (susceptible) (CLSI, 2009), as well as by PCR (Vannuffel et al., 1995).

Fifty selected MR-CoNS strains isolated from catheters $(n=15)$, blood $(n=15)$, bone $(n=9)$, two each from bronchial lavage and urine, and one each from an abscess, cerebrospinal fluid, eye, pleural effusion, synovial fluid, tracheal aspirate and wound secretion were studied further. The selected clinical isolates were collected from patients between 0 and 89 years of age, including nine newborns. MR-CoNS with uncertain biochemical patterns defined by API galleries analysis were examined further by amplification and sequencing of the $16 \mathrm{~S}$ rRNA gene using primers described previously (Pei et al., 2004). All sequencing was performed at the Instituto de Biotecnología de la Universidad Nacional Autónoma de México. Bacterial isolates were stored in Brucella broth containing $15 \%$ glycerol at $-70{ }^{\circ} \mathrm{C}$. Only one isolate per patient was included.

Antimicrobial susceptibility assays. Susceptibility testing was performed by broth microdilution using panels from Sensititre (TREK Diagnostic Systems) as described by the manufacturer. For all assays, the assay control organism (S. aureus ATCC 29213) and the susceptibility breakpoints were those recommended by the Clinical and Laboratory Standards Institute (CLSI, 2009). The interpretive breakpoint used for tigecycline was $\leqslant 0.5 \mu \mathrm{g} \mathrm{ml}^{-1}$ (susceptible) (Andrews \& Working Party for the British Society for Antimicrobial Chemotherapy, 2009).

SCCmec typing and PFGE. Preparation of template DNA and SCCmec, ccr and mec class typing were performed as described previously (Zhang et al., 2005). All SCCmec typing was performed twice. PFGE was carried out as described previously for $S$. aureus (Murchan et al., 2003) using a CHEF-DRIII instrument (Bio-Rad
Laboratories) on Staphylococcus epidermidis clinical isolates. Patterns were analysed and further interpreted according to the criteria of Tenover et al. (1995).

Statistical analysis. The significance between antibiotic profiles and SCCmec profiles was determined using a $\chi^{2}$ test. A value of $P<0.05$ was considered significant. Epi Info version 3.2.2 software (Centers for Disease Control and Prevention, GA, USA) was used for statistical analysis.

\section{RESULTS AND DISCUSSION}

\section{Staphylococci identified}

We evaluated the distribution of SCCmec types in CoNS isolated from patients at the Hospital Universitario Dr José Eleuterio Gonzalez over a 6-month period. From 215 clinical isolates included in the study, 149 were MR-CoNS and we randomly selected 50 isolates for further studies. Among the 50 selected MR-CoNS clinical isolates, as reported by others in similar studies, S. epidermidis was the most common species identified $(n=26)$ followed by Staphylococcus haemolyticus $(n=13)$ (Mombach Pinheiro Machado et al., 2007; Ruppé et al., 2009) (Table 1). Species identification of 17 of the isolates, including some Staphylococcus haemolyticus, and all Staphylococcus cohnii, Staphylococcus hominis and the single Staphylococcus sciuri, Staphylococcus pasteuri and Staphylococcus pettenkoferi isolates was confirmed by PCR and partial sequencing of the $16 \mathrm{~S}$ rRNA gene. The fragments obtained were compared with GenBank sequence entries using the BLAST algorithm (http://www.ncbi.nlm.nih.gov/BLAST).

For the recently described $S$. pettenkoferi, the sequence gave $99 \%$ identity with $S$. pettenkoferi strains SNUBH406 (GenBank accession no. FJ222447.1), TPL06 (EU373375.1), K6999 (AM265622.1), 229 (DQ538517.1), 230 (DQ538518.1) and 231 (DQ538519.1) and the A6664 (DQ538520) strain previously described by Trülzsch et al. $(2002,2007)$. Using the API Staph V4.0 identification system (bioMérieux), this strain was originally identified as Kocuria varians with an identification probability of $94.4 \%$.

The single $S$. pasteuri isolate was identified as $S$. aureus using the API Staph V4.0 identification system, with an identification probability of $96.9 \%$. The coagulase result was confirmed as negative. For the $S$. pasteuri isolate, the sequence gave $100 \%$ identity with S. pasteuri strains D4027 (FJ161258.1), JS10 (FJ205745.1) and NQ20 (EU919211.1).

\section{SCCmec types identified}

Among the MR S. epidermidis (MRSE) isolates examined, three harboured SCCmec type III, five had both III and IVa elements and eight harboured SCCmec type IVa (Table 1). The most frequent SCCmec element for S. epidermidis or any other species examined was IVa, which was recently described as the predominant type among S. epidermidis clinical isolates by Jamaluddin et al. (2008) in a Japanese population. In addition, in a long-term care facility in 
Finland, the distribution of SCCmec types in S. epidermidis was diverse, with the majority belonging to type IV (33\%), followed by type V (18\%) (Ibrahem et al., 2009). A report that included 44 strains isolated between 1973 and 1983 from blood showed that 16 strains (36\%) harboured SCCmec type IV (Wisplinghoff et al., 2003). In addition, Ruppé et al. (2009) described 75 MRSE strains from four countries, 34 of which were non-typable for SCCmec. Among the typable strains, type IV was the most common (27/75), followed by type V (13/75) (Ruppé et al., 2009). In contrast, Mombach Pinheiro Machado et al. (2007) found only 1/87 MRSE strains harbouring SCCmec type IV, with the most frequent MRSE SCCmec type being type III-IV (30/87). In our study, only $15 \%$ of S. epidermidis strains were untypable for SCCmec. Furthermore, the isolation of strains that amplified two types of SCCmec [III and IVa (five isolates), III and V (six isolates), and II and V (four isolates)] strongly suggests that new variants may be present in CoNS and may have a different impact on drug resistance. The typing of isolates that amplified two SCCmec types was confirmed by using single primers for each locus.

Evidence has suggested horizontal transfer of SCCmec from MR S. haemolyticus to meticillin-susceptible $S$. aureus strains, resulting in the creation of a new MRSA clone that could result in a potential outbreak (Berglund \& Söderquist, 2008). This concern underlines the importance of studying the prevalence of SCCmec in all CoNS strains.

In this study, we obtained only one isolate each of S. sciuri, S. pasteuri and S. pettenkoferi. The MR S. pettenkoferi isolate harboured SCCmec type IVd. An alignment of the DNA sequence of type IVd SCCmec of $S$. pettenkoferi and $S$. aureus type IV.4 (IVd) (GenBank accession no. AB097677.1) showed $100 \%$ sequence identity (identities $=848 / 848$ ), as did the alignment with $S$. aureus type IVd cassette chromosome mec (GenBank accession no. EF634484.1) (identities $=746 / 746$ ). To our knowledge, this is the first description of an S. pettenkoferi mecApositive isolate possessing SCCmec-like type IVd and this subtype had $100 \%$ homology to SCCmec IVd from $S$. aureus in the region sequenced. S. pettenkoferi was described in 2007 (Trülzsch et al., 2007) and has been reported as a causative agent of osteomyelitis (Loïez et al., 2007) and bloodstream and wound infections (Song et al., 2009; Trülzsch et al., 2002). The S. pettenkoferi strain reported here was isolated from a prematurely born (male) neonate (gestation age 30.1 weeks) who presented with surfactant deficiency, respiratory distress syndrome and venoclysis as predisposing factors. This strain is susceptible only to tigecycline and minocycline.

The single $S$. pasteuri isolate was isolated from bone in a newborn female with trisomy 21 and interauricular and interventricular communication, who had had multiple transfusions of blood and platelets. Interestingly, this particular species has been isolated from a leukaemic patient with bacteraemia (Savini et al., 2009a) and as a contaminant of platelet units (Savini et al., 2008, 2009b). To our knowledge, this is the first description of the presence of SCCmec in S. pasteuri and of the isolation of this species from bone.

The single MR S. pasteuri isolate harboured SCCmec type I. The alignment of type I SCCmec of S. pasteuri and S. aureus NCTC 10442 showed $100 \%$ sequence identity.

\section{PFGE genotyping and genotype cluster distribution}

Evaluation of banding patterns revealed an S. epidermidis clone with $100 \%$ homology in the PFGE patterns that amplified for both SCCmec III and V in samples 965, 1439, 1543, 1955 and 1981 (Fig. 1). This clone was isolated over a period slightly longer than 3 months (30 June 2006 to 4 October 2006). It is not likely that this clone could transmit these genetic elements to $S$. aureus isolates because it has been shown that the type $3 \mathrm{ccr}$ has lost the function of excising and integrating SCCmec into the staphylococcal chromosome. Instead, MRSE carrying SCCmec type IV is probably a reservoir of SCCmec that can be transferred to other species. The most frequent species and genotype of MR-CoNS isolated in our hospital was S. epidermidis SCCmec type IVa and these isolates showed high diversity. In Fig. 1, we have shown the only isolates with the same

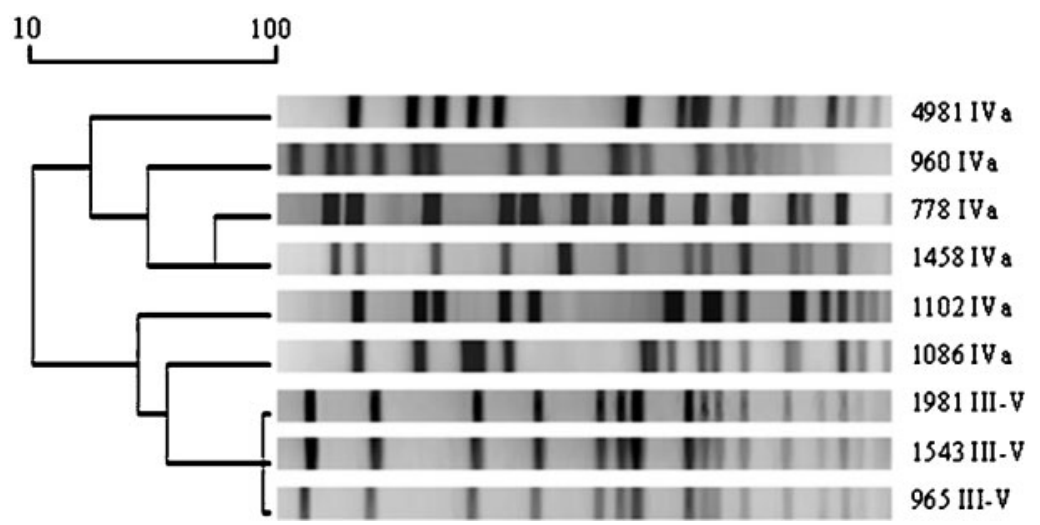

Fig. 1. PFGE dendrogram comparing representative $S$. epidermidis clones from the Hospital Universitario $\mathrm{Dr}$ José Eleuterio Gonzalez. The SCCmec type is included. The bar represents similarity. Similarity coefficients were generated from a similarity matrix calculated with the Jaccard coefficient using SPSS 10.0 software. 
PFGE pattern and some examples of the diversity found in the SCCmec IVa. All other PFGE patterns were completely different and no major cluster was detected among these strains.

\section{Antibiotic susceptibility testing}

The results of susceptibility testing are shown in Table 1 . In this study, we detected the previously described high resistance to antibiotics associated with the presence of SCCmec type III (Ito et al., 2001), although the only statistically significant association found was the carriage of SCCmec type III with resistance or intermediate resistance to meropenem $(P<0.05)$. Interestingly, three out of four strains that amplified only SCCmec III were resistant to tigecycline and the strains that amplified SCCmec type III plus another type (III and IVa, or III and V) were all susceptible to this drug.

In conclusion, we confirmed the high genetic diversity among the MR-CoNS isolates studied. This is the first report describing $S$. pettenkoferi and S. pasteuri carrying SCCmec elements and the first description of an $S$. epidermidis clone that amplified both SCCmec type III and $\mathrm{V}$ elements. These data are important not only for defining hospital control strategies, but also for shedding light on the heterogeneous pool of SCCmec types present in CoNS strains, which may act as a source of virulence factors for more pathogenic $S$. aureus strains.

\section{ACKNOWLEDGEMENTS}

We thank Maria de la Luz Acevedo and Carlos Paz for their technical assistance and Dr Sergio Lozano for reviewing this manuscript.

\section{REFERENCES}

Andrews, J. \& Working Party for the British Society for Antimicrobial Chemotherapy (2008). BSAC Methods for Antimicrobial Susceptibility Testing. http://www.bsac.org.uk/_db/_ documents/version_7.pdf.

Baba, T., Kuwahara-Arai, K., Uchiyama, I., Takeuchi, F., Ito, T. \& Hiramatsu, K. (2009). Complete genome sequence of Macrococcus caseolyticus strain JCSCS5402, [corrected] reflecting the ancestral genome of the human-pathogenic staphylococci. J Bacteriol 191, 1180-1190.

Bannerman, T. L. \& Peacock, S. J. (2007). Staphylococcus, Micrococcus and other catalase-positive cocci. In Manual of Clinical Microbiology, 9th edn, pp. 390-404. Edited by P.R. Murray, E. J. Baron, J. H. Jorgensen, M. A. Pfaller \& M. L. Landry. Washington, DC: American Society for Microbiology.

Berglund, C. \& Söderquist, B. (2008). The origin of a methicillinresistant Staphylococcus aureus isolate at a neonatal ward in Sweden possible horizontal transfer of a staphylococcal cassette chromosome mec between methicillin-resistant Staphylococcus haemolyticus and Staphylococcus aureus. Clin Microbiol Infect 14, 1048-1056.

Chongtrakool, P., Ito, T., Ma, X. X., Kondo, Y., Trakulsomboon, S., Tiensasitorn, C., Jamklang, M., Chavalit, T., Song, J. H. \& Hiramatsu, K. (2006). Staphylococcal cassette chromosome mec (SCCmec) typing of methicillin-resistant Staphylococcus aureus strains isolated in 11 Asian countries: a proposal for a new nomenclature for SCCmec elements. Antimicrob Agents Chemother 50, 1001-1012.

CLSI (2009). Performance Standards for Antimicrobial Susceptibility Testing; Eighth Informational Supplement, CLSI document M100-S19. Wayne, PA: Clinical and Laboratory Standards Institute.

Curtis, C. \& Shetty, N. (2008). Recent trends and prevention of infection in the neonatal intensive care unit. Curr Opin Infect Dis 21, 350-356.

Falcone, M., Campanile, F., Giannella, M., Borbone, S., Stefani, S. \& Venditti, M. (2007). Staphylococcus haemolyticus endocarditis: clinical and microbiologic analysis of 4 cases. Diagn Microbiol Infect Dis 57, 325-331.

Hanssen, A. M. \& Ericson Sollid, J. U. (2006). SCCmec in staphylococci: genes on the move. FEMS Immunol Med Microbiol 46, 8-20.

Ibrahem, S., Salmenlinna, S., Virolainen, A., Kerttula, A. M., Lyytikäinen, O., Jägerroos, H., Broas, M. \& Vuopio-Varkila, J. (2009). Carriage of methicillin-resistant staphylococci and their SCCmec types in a long-term-care facility. J Clin Microbiol 47, 32-37.

Ito, T., Katayama, Y., Asada, K., Mori, N., Tsutsumimoto, K., Tiensasitorn, C. \& Hiramatsu, K. (2001). Structural comparison of three types of staphylococcal cassette chromosome mec integrated in the chromosome in methicillin-resistant Staphylococcus aureus. Antimicrob Agents Chemother 45, 1323-1336.

Jamaluddin, T. Z., Kuwahara-Arai, K., Hisata, K., Terasawa, M., Cui, L., Baba, T., Sotozono, C., Kinoshita, S., Ito, T. \& Hiramatsu, K. (2008). Extreme genetic diversity of methicillin-resistant Staphylococcus epidermidis strains disseminated among healthy Japanese children. J Clin Microbiol 46, 3778-3783.

Katayama, Y., Ito, T. \& Hiramatsu, K. (2000). A new class of genetic element, staphylococcus cassette chromosome mec, encodes methicillin resistance in Staphylococcus aureus. Antimicrob Agents Chemother 44, 1549-1555.

Loïez, C., Wallet, F., Pischedda, P., Renaux, E., Senneville, E., Mehdi, N. \& Courcol, R. J. (2007). First case of osteomyelitis caused by "Staphylococcus pettenkoferi". J Clin Microbiol 45, 1069-1071.

Lyytikäinen, O., Lumio, J., Sarkkinen, H., Kolho, E., Kostiala, A., Ruutu, P. \& Hospital Infection Surveillance Team (2002). Nosocomial bloodstream infections in Finnish hospitals during 1999-2000. Clin Infect Dis 35, e14-e19.

Ma, X. X., Ito, T., Tiensasitorn, C., Jamklang, M., Chongtrakool, P., Boyle-Vavra, S., Daum, R. S. \& Hiramatsu, K. (2002). Novel type of staphylococcal cassette chromosome mec identified in communityacquired methicillin-resistant Staphylococcus aureus strains. Antimicrob Agents Chemother 46, 1147-1152.

Mombach Pinheiro Machado, A. B., Reiter, K. C., Paiva, R. M. \& Barth, A. L. (2007). Distribution of staphylococcal cassette chromosome mec (SCCmec) types I, II, III and IV in coagulase-negative staphylococci from patients attending a tertiary hospital in southern Brazil. J Med Microbiol 56, 1328-1333.

Murchan, S., Kaufmann, M. E., Deplano, A., de Ryck, R., Struelens, M., Zinn, C. E., Fussing, V., Salmenlinna, S., Vuopio-Varkila, J. \& other authors (2003). Harmonization of pulsed-field gel electrophoresis protocols for epidemiological typing of strains of methicillin-resistant Staphylococcus aureus, a single approach developed by consensus in 10 European laboratories and its application for tracing the spread of related strains. J Clin Microbiol 41, 1574-1585.

Musser, J. M. \& Kapur, V. (1992). Clonal analysis of methicillinresistant Staphylococcus aureus strains from intercontinental sources: association of the mec gene with divergent phylogenetic lineages implies dissemination by horizontal transfer and recombination. J Clin Microbiol 30, 2058-2063. 
Pei, Z., Bini, E. J., Yang, L., Zhou, M., Francois, F. \& Blaser, M. J. (2004). Bacterial biota in the human distal esophagus. Proc Natl Acad Sci U S A 101, 4250-4255.

Ruppé, E., Barbier, F., Mesli, Y., Maiga, A., Cojocaru, R., Benkhalfat, M., Benchouk, S., Hassaine, H., Maiga, I. \& other authors (2009). Diversity of staphylococcal cassette chromosome mec structures in methicillinresistant Staphylococcus epidermidis and Staphylococcus haemolyticus strains among outpatients from four countries. Antimicrob Agents Chemother 53, 442-449.

Savini, V., Catavitello, C., Pompetti, F., Passeri, C., Di Zacomo, S., Esattore, F., lacone, A. \& D'Antonio, D. (2008). Contamination of a donated platelet unit by Staphylococcus pasteuri. J Infect 57, 494-496.

Savini, V., Catavitello, C., Carlino, D., Pompilio, A., Balbinot, A., Piccolomini, R., Di Bonaventura, G. \& D’Antonio, D. (2009a). Staphylococcus pasteuri bacteraemia in patient with leukaemia. J Clin Pathol 62, 957-958.

Savini, V., Bianco, A., Catavitello, C., Balbinot, A., Pompilio, A., Piccolomini, R., di Bonaventura, G. \& D’Antonio, D. (2009b). Meticillin-heteroresistant Staphylococcus pasteuri from an apheresis platelet product. J Med Microbiol 58, 1527-1528.

Song, S. H., Park, J. S., Kwon, H. R., Kim, S. H., Kim, H. B., Chang, H. E., Park, K. U., Song, J. \& Kim, E. C. (2009). Human bloodstream infection caused by Staphylococcus pettenkoferi. J Med Microbiol 58, 270-272.

Tenover, F. C., Arbeit, R. D., Goering, R. V., Mickelsen, P. A., Murray, B. E., Persing, D. H. \& Swaminathan, B. (1995). Interpreting chromosomal DNA restriction patterns produced by pulsed-field gel electrophoresis: criteria for bacterial strain typing. J Clin Microbiol 33, 2233-2239.
Trülzsch, K., Rinder, H., Trcek, J., Bader, L., Wilhelm, U. \& Heesemann, J. (2002). Staphylococcus pettenkoferi," a novel staphylococcal species isolated from clinical specimens. Diagn Microbiol Infect Dis 43, 175-182.

Trülzsch, K., Grabein, B., Schumann, P., Mellmann, A., Antonenka, U., Heesemann, J. \& Becker, K. (2007). Staphylococcus pettenkoferi sp. nov., a novel coagulase-negative staphylococcal species isolated from human clinical specimens. Int J Syst Evol Microbiol 57, 1543-1548.

Vannuffel, P., Gigi, J., Ezzedine, H., Vandercam, B., Delmee, M., Wauters, G. \& Gala, J. L. (1995). Specific detection of methicillinresistant Staphylococcus species by multiplex PCR. J Clin Microbiol 33, 2864-2867.

Viale, P. \& Stefani, S. (2006). Vascular catheter-associated infections: a microbiological and therapeutic update. J Chemother 18, 235-249.

Wisplinghoff, H., Rosato, A. E., Enright, M. C., Noto, M., Craig, W. \& Archer, G. L. (2003). Related clones containing SCCmec type IV predominate among clinically significant Staphylococcus epidermidis isolates. Antimicrob Agents Chemother 47, 3574-3579.

Zhang, K., McClure, J. A., Elsayed, S., Louie, T. \& Conly, J. M. (2005). Novel multiplex PCR assay for characterization and concomitant subtyping of staphylococcal cassette chromosome mec types I to V in methicillin-resistant Staphylococcus aureus. J Clin Microbiol 43, 50265033.

Zhang, K., McClure, J. A., Elsayed, S. \& Conly, J. M. (2009). Novel staphylococcal cassette chromosome mec type, tentatively designated type VIII, harboring class A mec and type $4 \mathrm{ccr}$ gene complexes in a Canadian epidemic strain of methicillin-resistant Staphylococcus aureus. Antimicrob Agents Chemother 53, 531-540. 